Giving Well 



\section{Giving Well}

The Ethics of Philanthropy

\section{EDITED BY}

Patricia Illingworth, Thomas Pogge, and Leif Wenar

\section{OXFORD}




\section{OXFORD}

UNIVERSITY PRESS

Oxford University Press, Inc., publishes works that further

Oxford University's objective of excellence

in research, scholarship, and education.

Oxford New York

Auckland Cape Town Dar es Salaam Hong Kong Karachi

Kuala Lumpur Madrid Melbourne Mexico City Nairobi

New Delhi Shanghai Taipei Toronto

With offices in

Argentina Austria Brazil Chile Czech Republic France Greece

Guatemala Hungary Italy Japan Poland Portugal Singapore

South Korea Switzerland Thailand Turkey Ukraine Vietnam

Copyright @ 2011 by Oxford University Press, Inc.

Published by Oxford University Press, Inc.

198 Madison Avenue, New York, New York 10016

www.oup.com

Oxford is a registered trademark of Oxford University Press.

All rights reserved. No part of this publication may be reproduced, stored in a retrieval system, or transmitted, in any form or by any means, electronic, mechanical, photocopying, recording, or otherwise, without the prior permission of Oxford University Press.

Library of Congress Cataloging-in-Publication Data

Giving well: the ethics of philanthropy / edited by Patricia Illingworth, Thomas Pogge, and Leif Wenar.

p. $\mathrm{cm}$.

ISBN 978-0-19-973907-3

1. Charities-Moral and ethical aspects. I. Illingworth, Patricia M. L., 1954- II. Pogge, Thomas Winfried Menko. III. Wenar, Leif.

HV41.G525 2010

$174^{\prime} .93617-\mathrm{dc} 22 \quad 2010008770$

$\begin{array}{lllllllll}9 & 8 & 7 & 6 & 5 & 4 & 3 & 2 & 1\end{array}$

Printed in the United States of America

on acid-free paper 


\section{Contents}

Contributors

vii

Introduction: The Ethics of Philanthropy

Patricia Illingworth, Thomas Pogge, and Leif Wenar

1 What Should a Billionaire Give-and What Should You? Peter Singer

2 Obligations of Justice and Beneficence to Aid the Severely Poor Elizabeth Ashford

3 How International Nongovernmental Organizations Should Act

Thomas Pogge

4 The Valmont Effect: The Warm-Glow Theory of Philanthropy Jon Elster

$5 \quad$ Aiding the World's Poor: New Challenges for Donor States Roger C. Riddell

6 Poverty Is No Pond: Challenges for the Affluent Leif Wenar

7 Ethics in Translation: Principles and Power in the Philanthropic Encounter Alex de Waal

8 Global Philanthropy and Global Governance: The Problematic Moral Legitimacy of the Relationship between Global Civil Society and the United Nations Kenneth Anderson

9 Toward a Political Theory of Philanthropy Rob Reich

10 Giving Back: Norms, Ethics, and Law in the Service of Philanthropy 
11 The Funder as Founder: Ethical Considerations of the Philanthropic Creation of Nonprofit Organizations James Shulman

12 The Unfulfilled Promise of Corporate Philanthropy Thomas W. Dunfee

13 Philanthropy, Self-Interest, and Accountability: American Universities and Developing Countries Devesh Kapur

Index 


\title{
How International Nongovernmental Organizations Should Act
}

\author{
Thomas Pogge
}

We inhabit this world with large numbers of people who are very badly off through no fault of their own. The official statistics are overwhelming: 1,020 million people (more than ever before) are chronically undernourished, ${ }^{1} 884$ million lack access to safe drinking water, ${ }^{2}$ 2,500 million lack access to improved sanitation, ${ }^{3}$ 2,000 million lack access to essential medicines, ${ }^{4} 924$ million lack adequate shelter, ${ }^{5} 1,600$ million lack electricity, ${ }^{6}$ 796 million adults are illiterate, ${ }^{7} 218$ million children are child laborers, ${ }^{8}$ and 1,400 million consume less per month than could be bought in the United States for \$38 in 2005. ${ }^{9}$ Roughly one third of all human deaths, 18 million annually, are the result of poverty-related causes, straightforwardly preventable through better nutrition, safe drinking water, cheap rehydration packs, vaccines, antibiotics, and other medicines. ${ }^{10}$ People of color, females, and the very young are heavily overrepresented among the global poor, and hence also among those suffering the staggering effects of severe poverty. ${ }^{11}$

The people appearing in these statistics live in distant, underdeveloped countries. Some of us in the rich countries care about and seek to improve their circumstances. However, it is difficult to do this on one's own, so we cooperate with others. We can do this politically, trying to get our governments and corporations to do less harm and more good in poor countries. We can also do this by supporting international nongovernmental organizations (INGOs) that offer to pool our contributions and make such funds effective toward human rights, development, and humanitarian goals.

Not enough of us act in either of these ways. The costs and opportunity costs of a full-fledged effort to eradicate severe poverty and its attendant medical and educational deficits worldwide might amount to some $\$ 300$ billion annually_at least initially, because costs would decrease dramatically in future years. ${ }^{12}$ This amount is affordable, even if it came from just the most affluent countries containing about $16 \%$ of the world's population. The gross national incomes of these countries sum to about $\$ 42$ trillion, ${ }^{13} 140$ times larger than the cost of eradicating severe poverty. 
But $\$ 300$ billion annually is a huge amount relative to the roughly $\$ 28$ billion the rich countries actually spend each year to protect the global poor: about $\$ 15.5$ billion in official development assistance for basic social services $^{14}$ and about $\$ 12.6$ billion ( $0.03 \%$ of gross national income) through INGOs. ${ }^{15}$

International nongovernmental organizations face difficult moral decisions about how to spend their funds. In the world as it is, with massive human deprivation and little money to reduce it, any decisions an INGO makes is likely to affect many lives severely. To put it bluntly, an INGO must often make decisions that will certainly lead to many deaths, because spending one's limited funds on trying to protect some persons is tantamount to leaving others to their fate. This is an awesome responsibility.

Contributors also face such awesome choices. Some INGOs are wasteful and corrupt, and contributions to them may then prevent no serious harm at all. And even when I am pretty sure that my contribution to one INGO will enable it to prevent deaths, it is clear that there are other INGOs for which the same is true. Different INGOs prevent different deaths. By contributing to one rather than another, I am, then, indirectly deciding who will live and who will die. Obviously, spreading my contribution over all effective INGOs is no solution, because each will then receive much less than if I had given my whole contribution to it alone.

International nongovernmental organizations can realize large economies of scale, because they deliberate and deliver for many. Choosing an INGO to do this for them, contributors are giving with a triple trust. We trust that the INGO has developed carefully formulated moral priorities governing how the collected money should be spent. We trust that this INGO has procured the information and inventive talent it needs to implement the priorities well through the funding of specific projects. And we trust that this INGO is funding the chosen projects efficiently. Although we can check up on any INGO in various ways, there remains a large element of trust that most contributors cannot eliminate at reasonable cost.

The trust of contributors saddles INGO staff with a second responsibility: They must not let their contributors down by setting the wrong moral priorities, by funding infeasible or counterproductive projects, or by frittering money away through carelessness and corruption. This responsibility cannot be discharged by ensuring that contributors never learn that their trust has been abused and their funds wasted. As a contributor, I care about averting serious harm. To be sure, I feel better believing that my contribution has succeeded than believing it has failed. Still, my objective is to avert serious harm-not merely to believe that I have done so. Whether an INGO lives up to its contributors' trust depends, then, solely on whether it actually makes their contributions effective through morally important projects. 
Fortunately, the two responsibilities largely coincide in content. An INGO that fulfills its triple task well does no wrong either to its contributors or to the poor and oppressed abroad-even though it can protect only a small fraction of the latter.

The remainder of this chapter offers some thoughts on the first task of INGOs: developing moral priorities governing how the entrusted money should be spent. These thoughts fall short of clear-cut answers. They merely try to assemble the more important moral considerations that must inform any full-blown answer to the question of moral priorities. In investigating this question, let us bear two points in mind: (1) reflections on the first task are not wholly separable from the other two and (2) predictions about what an INGO can do and how cost-effectively it can do it are relevant to what moral priorities it should set. Furthermore, an INGO is not merely an actor in its own right; it is also an agent and trustee for its contributors. It must then reflect not merely on its own moral responsibilities, but also on its contributors' moral responsibilities, which these contributors entrust it with discharging.

\section{FOUR BASIC COUNTERS}

Let us begin with four moral considerations that may seem obvious but still need clarification.

(A) Other things (including cost) being equal, it is morally more important to protect a person from greater serious harm than from lesser.

The key concept in this proposition is that of serious harm. In the current context, I propose to define harm as shortfalls persons suffer in their health, civic status (civil and political rights, respect within their community), or standard of living relative to the ordinary needs and requirements of human beings. This rough definition has three noteworthy features:

1. It is sufficientarian in its suggestion of some threshold of minimal sufficiency to which shortfalls are relative. Those living at or above this threshold suffer no serious harm at all. To save words, I use harm in the sense of serious harm from now on.

2. By focusing on the basic needs of persons, the definition takes account of the decreasing marginal significance of resources (such as medical care, civil rights, education, and money).

3. The definition recognizes as harm any shortfalls, irrespective of cause. Thus, severe poverty is harm regardless of whether it is the result of a drought, a person's social status as a bonded laborer, or her own earlier recklessness. Harm caused in the last way is morally less important; the "other things being equal" clause allows for this. 
To illustrate the first two features, suppose that some planned INGO project in India would add 100 rupees (Rs.) per month to someone's income. Feature (1) suggests that this addition may be morally insignificant because the relevant person's standard of living is already minimally adequate. She is suffering no harm from poverty as it is, and the project thus would not protect her from harm (although it may, of course, protect others). Feature (2) suggests that greater income deficits constitute disproportionately greater harm. Thus, an Indian subsisting on Rs. 200 per month below a minimally adequate standard of living is, other things being equal, suffering more than twice the harm of someone living only Rs. 100 per month below a minimally adequate standard of living. Thus, an extra Rs. 100 per month for someone living Rs. 200 per month below a minimally adequate standard of living protects her from greater harm than it would if she lived only Rs. 100 per month below minimal sufficiency. Put in general terms, incremental resources generally are morally more important the less its recipients have. What matters morally is not the project's impact on persons' resources, but its impact on their standard of living, on their ability to meet their basic human needs.

The further specification of proposition (A) confronts three main issues. One is what should count as harm and what weight should be attached to harm of different types. The development and defense of a suitable harm metric is evidently a complex task. I bypass this task here for reasons of space.

Another issue is to what extent effects should be taken into account. When a child suffers severe malnutrition, her mental and physical development is stunted, and this imposes additional harm on her throughout her life. It seems evident that such effects should count; preventing that child's malnutrition also prevents her suffering this later harm. The focus should be, then, on the overall harm reduction accomplished for the child's life as a whole.

But if effects are counted in this way, then protecting those with greater life expectancy will often be morally more important than protecting those with lesser life expectancy. Even lifesaving efforts, it would seem, should then generally be focused on younger people insofar as death would impose on them a greater loss. Although widely accepted within the medical profession, these implications may seem problematic to some who are also attracted to the view that the whole future of any one person has the same moral import as the whole future of any other person, regardless of how much time each is expected to have left to live.

The last issue concerns disagreements between those threatened by harm and those seeking to protect them (INGOs and their contributors) about what is to count as harm and how to count it. A woman may believe that cliterodectomy is normal and necessary, no more harmful than the extraction of a rotten tooth, or that the subordination of women in the household and in the public sphere is holy and good. We may believe that women are harmed by their subordination and also by being indoctrinated 
to believe that this subordination isn't harmful to them. If so, do we have moral reason to protect that woman from harm she does not recognize as such? A man may believe that he would suffer much greater harm by failing to fulfill an expensive religious duty than by being undernourished. We may believe the opposite. If so, do we have more moral reason to enable him to fulfill his supposed religious duty or to enable him to buy food? Would it not be paternalistic to impose our own notion of harm on those whom we are seeking to protect?

(B) Other things (including cost) being equal, it is morally more important to protect persons from harm the more such harm they would otherwise be suffering.

Given how I have conceived harm-in terms of the ordinary needs and requirements of human beings-(B) is independent of (A) in that the decreasing marginal significance of resources is already incorporated into the conception of harm. This conception already takes account of the fact that extra income of Rs. 60 per month has as much of an impact on the standard of living of the typical extremely poor Indian as, say, Rs. 100 per month of extra income has on the standard of living of the typical merely poor Indian. Proposition (B) thus holds that-quite apart from taking account of the decreasing marginal significance of resources-we should prioritize those who are worse off (defined in terms of harm).

The point is straightforward in cases in which the decreasing marginal significance of resources plays no role. Thus, consider an INGO that supplies poor households with a smart fuel-efficient stove that greatly reduces hazardous indoor air pollution and time spent gathering firewood. With nowhere near enough stoves for all poor households, the INGO must choose whether to supply the stoves to one rural area inhabited by extremely poor people or to another less-poor area. People in both groups would realize equal harm reductions (gains in life expectancy, health, and so forth), and even the less-poor people could never afford to buy such a stove on their own. Even though the two groups thus do not differ in terms of achievable harm reduction, proposition (B) directs the INGO to decide in favor of the extremely poor.

One might fix this point terminologically by drawing a distinction between the magnitude and the moral value, or moral importance, of any harm reduction. Although an extra Rs. 60 per month (a smart stove) is no more significant to a typical extremely poor person than an extra Rs. 100 per month (a smart stove) is to a merely poor one (the harm reductions achieved are the same), the former gain is still morally more important than the latter (the harm reduction it achieves is of greater moral value).

Proposition (B) holds, then, that the harm reduction achieved for one person may be both smaller and yet also morally more valuable than the harm reduction achieved for another. This can happen when the former person is exposed to greater overall harm than the latter. Insofar as scarce resources force INGOs to choose between such achievements, (B) directs 
them to prefer a smaller but morally more valuable harm reduction for one person over a larger but less valuable harm reduction for another. Equivalently, I will say that INGOs should aim for the greater harm protection, defined as reflecting the moral importance (moral value) of harm reductions rather than their magnitude.

The further specification of proposition (B) confronts three main issues, roughly parallel to those encountered in the specification of (A). One is about how the moral value of a harm reduction depends on how badly off its beneficiary is. ${ }^{16}$ As in (A), INGOs should aim to achieve as much harm reduction as possible for those exposed to the greatest harm. They must also integrate the two maximands by specifying the moral importance of any harm reduction an INGO project might achieve for some particular person as a function of the magnitude of this harm reduction and the level of overall harm suffered by the person to be protected. This might be done symmetrically, weighing each factor equally; or asymmetrically, giving more weight to either factor. There is much room for reasonable disagreement about how strongly those who are worse off should be prioritized. Different INGOs will fix this priority at different levels. Each particular INGO, however, can meaningfully compare candidate projects only if it chooses a unique level, using the same constant for assessing the impact of all its candidate projects on the individuals they affect.

A further issue faced in the specification of proposition (B) is how much of persons' lives we should consider for determining how badly off they are. At one extreme, one might attend to their current situation only-that only harms suffered now are relevant. At the other, one could take into account their entire past and estimated future, their life as a whole - the fact that people have, years ago, suffered through a horrible drought would strengthen one's reasons to combat malaria among them rather than elsewhere.

(C) Other things (including cost) being equal, it is morally more important to achieve some given harm protection for more persons than for fewer. Here, aggregate harm protection is a linear function of the number of persons protected. Generally, the moral value of several harm reductions is the sum of their moral values.

Proposition (C) makes three progressively stronger claims. Its first and weakest claim is ordinal: Other things being equal, if $n>m$, then achieving some harm protection for $n$ persons has more moral value than achieving the same harm protection for $m$ persons. The second, stronger claim is cardinal: Other things being equal, achieving some harm protection for $n$ persons has $n / m$ times as much moral value than achieving the same harm protection for $m$ persons. The third, strongest claim extends this additive aggregation of moral values to nonequivalent harm protections.

Accepting the strongest claim of proposition (C) means that the moral value or importance of a project is the sum of the moral values of the harm reductions this project achieves for the individuals it affects. 
(D) Other things (including harm protection) being equal, an INGO should choose cheaper candidate projects over more expensive ones. More specifically, the choice-worthiness of candidate projects is inversely proportional to their cost.

This is motivated by the thought that any INGO's resources are scarce relative to the morally important projects it might undertake. Any INGO should prefer to implement cheaper projects, because it can then achieve more of what is morally important.

Taking all four propositions together, the moral principle governing INGO conduct can then, at first approximation, be formulated as follows:

(ABCD) Other things being equal, an INGO should choose among candidate projects on the basis of the cost-effectiveness of each project, defined as its moral value divided by its cost. Here, a project's moral value is the harm protection it achieves-that is, the sum of the moral values of the harm reductions (and increases) this project would bring about for the individual persons it affects.

This principle is underspecified in various ways-with regard to its notion of harm as well as with regard to its "other things being equal" clause. I devote most of the remainder of this essay to the exploration of this clause-that is, to the question: What other factors come into play to affect the balance of reasons bearing on the ranking of candidate projects?

\section{Distributive Fairness}

One significant factor that may render other things unequal is the factor of distributive fairness. Many INGO managers are strongly committed to a particular ideal of fairness across countries: They think it unfair to spend more resources on protecting people in some countries than on protecting people in other countries merely because resources can be employed more cost-effectively in the former than in the latter. They believe that as long as resources can achieve some harm protection in a country, a fair share thereof should be allocated to this country even if the same resources could achieve much more elsewhere.

This commitment to distributive fairness among those who are working on harm reduction abroad manifests itself in the real world. International nongovernmental organizations and other relevant (governmental and intergovernmental) agencies would work very differently if they did not have this commitment. They would then concentrate the limited funds available for this purpose on locales that offer the most favorable environments for the cost-effective reduction of severe poverty. Some years ago, Collier and Dollar argued that these countries were, in order, Ethiopia, Uganda, and India. ${ }^{17}$ They estimated that-even excluding India and Bangladesh-a poverty-efficient reallocation of existing aid among all countries would reduce the average cost of lifelong poverty protection from $\$ 2,650$ per person to $\$ 1,387$ per person and would thus make it 
possible to save 19.1 million rather than only 10 million people from poverty. ${ }^{18}$ Such a reallocation would completely exclude several dozen poor countries where aid is inefficient, and would raise aid to other countries where the cost of lasting protection from poverty is as low as $\$ 600$ per person (Ethiopia) or $\$ 1,000$ (Uganda) per person. ${ }^{19}$

Details aside, Collier and Dollar are surely right: The existing allocation of funds for harm reduction efforts is highly inefficient, and concentrating on a few countries would greatly increase what these funds achieve by way of poverty eradication. Although there is much to dispute in their rough calculations, they do provide a real-world context for discussing the proposed distributive fairness constraint. Is it morally more important to protect an additional 9.1 million people from a life in poverty by concentrating our efforts on where we can be most cost-effective? Or is it morally more important to allocate scarce resources fairly across all countries in which poor people live?

It seems obvious to me that we should here decide against the proposed distributive fairness constraint and in favor of protecting more people. I recognize that if we concentrate on a few countries, we will do nothing to protect many very badly off people who, through no fault of their own, live elsewhere. However, if we spread our efforts fairly over all poor countries, then we will do nothing to protect even more people who are just as badly off and just as free of fault in their fate. Any conceivable allocation of available resources will leave many people exposed to a life of severe deprivation-people who ought to be protected. If we cannot fully protect everyone, then we should at least achieve as much as possible.

To make this choice more concrete, imagine an INGO that, with its limited resources, can either build two wells in Ethiopia, providing safe drinking water to 5,000, or else build one well in Chad, providing safe drinking water to 1,000 . The former project would protect many more people, but the latter would achieve a fairer distribution of INGO resources across countries because other funds have already been allocated to projects in Ethiopia. If we choose the former project, we can justify to the 1,000 Chadians our neglect of their plight by pointing to the disparity in numbers. However, how could we justify to the 5,000 Ethiopians our neglect of their plight if we chose the latter project? How could we explain to them that we find protecting them less important than protecting 1,000 Chadians who are no worse off than they are?

We would say that these funds should go to a project in Chad because other funds have already been allocated to projects in Ethiopia whereas no funds have yet been allocated anywhere in Chad. But is this a good reason? Our interlocutors can respond:"The projects elsewhere in Ethiopia do nothing to protect $u s$. So why should they affect the decision? We happen to live in the same country as people now protected by other projects. Why should this count against us? Why are we so much less worthy of protection than we would be if our province were a separate country?" 
Consider a hypothetical emergency rescue on the high seas. A large cruise ship has sunk in very cold waters and we are trying to save some of the scattered survivors by pulling them aboard our smaller vessel before they die in the icy waters. The passengers and crew of the cruise ship are nationals of many countries. If we simply try to save as many as possible, these countries would not be fairly represented among the rescued (according to whatever standard the advocates of a distributive fairness constraint care to specify). May we aim for fair representation of countries, then, even if this would make our rescue efforts less cost-effective and would thus lead to our saving fewer people? If the answer is negative, why must not INGOs, too, display fairness across individuals-giving equal weight to the interests of each and hence protecting as many as possible- at the expense of fairness across countries? The insistence on distributive fairness across countries goes against common commitments to the equal worth of all human beings, to the idea that we should treat all persons with equal concern irrespective of their nationality.

The advocates of distributive fairness across groups also face another problem: What about groups defined in terms of features other than nationality? If the allocation of resources must be fair across countries, must it then not also be fair across provinces, counties, religious denominations, generations, sexes, settlements of different sizes, and so forth? Affirmative answers add ever more-possibly inconsistent-fairness constraints, each of which will tend to reduce the cost-effectiveness of our harm protection efforts. Negative answers provoke the charge of inconsistency: What is so special about nationality? Why should we have to treat nationalities fairly, but not the other groupings mentioned?

Before concluding that the concern for fairness across groups must be set aside in deference to the very weighty concern to maximize harm protection, let us consider two special cases that are more problematic.

Imagine an acute famine emergency. An INGO is bringing in food, but, given its limited resources, it cannot ensure everyone's survival. No one can survive on a fair share of the available food. So, if some are to survive, the INGO must distribute its limited food supply selectively. But how to select? Consider two options. The INGO might select hungry persons at random up to the point where their minimal food requirements equal the available food supply. Alternatively, the INGO might opt for selection rules that maximize the expected number of survivors. Such rules would, in general terms, favor those whose minimal food requirements are smallest. They would, in particular, favor persons with more efficient metabolisms, children over adults, and women over men. How should the INGO staff proceed in such a horrifying situation?

In response to such questions, it is sometimes said that the INGO staff "should not play God." I find this idea unhelpful, because I cannot see what is supposed to follow from it. The decision about which distribution rule to use is ineluctably ours. The situation imposes this awesome choice on us, and we cannot evade the responsibility. Even if we run a lottery and 
even if we flee the scene, leaving desperate people to fight over the food we leave behind, we are still making a decision that determines who will live and who will die. We must face the question: How do we distribute the food?

Facing this question, I think we ought to apply optimizing selection rules to the situation. We ought to protect 20 men and 65 women, for example, if doing so enables 85 people to survive instead of the 80 that would survive if we chose to protect equal numbers of men and women.

This general rejection of distributive fairness constraints seems least plausible in cases in which the fact that some people are harder to protect is a result of injustice suffered by these very people. Thus, consider the decision that may be faced by an INGO constructing wells to ensure access to safe drinking water. Suppose this INGO normally rejects distributive fairness and builds wells only in urban areas, where population density is high, rather than in rural areas, where the same well would serve fewer people. But suppose further that the INGO operates in a country where the members of some despised minority religion are barred from living in urban areas (where their beliefs might "set a bad example") and are thus forced to inhabit isolated rural areas. In this context, one may well be inclined to reject the optimizing policy because it would, in effect, systematically aggravate the unjust disadvantage imposed on the members of the minority religion.

To see how much support this case can give to the idea of distributive fairness constraints, we must strip away at least two impurities. The case as described may evoke the thought that the members of the religious minority, suffering disdain and discrimination, are really worse off than the urban dwellers who would gain access to safe drinking water if the wells were built there. Insofar as this is true, propositions (A) and (B) already provide countervailing reasons that may tip the scales in favor of constructing the wells in minority areas. The case as described may also evoke the thought that those urban dwellers share in the disdain of, and collaborate in the discrimination against, the religious minority. This consideration might shift the balance of reasons against them, but for reasons of desert that have nothing to do with distributive fairness. To present the case as supporting distributive fairness constraints, let us then construct it by envisioning another equally despised religious minority, this one living in urban ghettos-a minority that is just as badly off, but does not share the widespread disdain others inflict on the first religious minority. Should our INGO here follow the optimizing policy and construct wells in the urban ghettos (where they will protect many members of the second minority) or should our INGO construct wells also in rural areas (where they will protect members of the first minority) even if this substantially reduces the overall number of people gaining access to safe drinking water? In the case so described, I do not find it difficult to endorse, for all the reasons discussed earlier, the first option at the expense of the suggested fairness constraints. 
I do not believe that the arguments I have presented settle the matter conclusively. However, they do convince me, for now, that the proposed ideals of distributive fairness should not constrain the straightforward application of $(\mathrm{ABCD})$. The "other things being equal" clause in this principle should not be read as permitting departures from cost-effectiveness for the sake of achieving an equalization of chances among needy individuals or a proportionate distribution of harm reduction efforts across countries or other collectivities.

\section{FURTHER CONSIDERATIONS}

Without claim to completeness, this section addresses five additional issues relevant to the proper specification of (ABCD).

\section{Extinction and Diversity}

(ABCD) conceives the moral value of any project in individualistic terms: as the sum of the moral values of the harm reductions (and increases) this project would bring about for the individual persons it affects. It may thereby leave out significant moral concerns. Suppose, for instance, that the cost-effective allocation of funds would exclude a certain region (the Amazon, say) in which certain nations or cultures are threatened with extinction. One may well think that when the last members of such a nation are killed or forced out of their ancestral lands, the moral loss is greater than the harm suffered by these individuals.

One may invoke the value of diversity to explain these intuitions in a way that fits the individualist paradigm: All human beings lose when the biological and cultural diversity of humankind is diminished. However, it is hard to establish that this loss to individuals can shift the balance of reasons away from, say, saving the lives of 5,000 starving Ethiopians toward saving the lives of 500 Amazon natives. Thus, it would seem that to accommodate those intuitions, normative individualism would have to be relaxed somewhat to make room for the realization that not every morally serious loss is harm suffered by individual human beings. The demise or demoralization of a nation with its own culture (language, religion, shared way of life) can be a serious loss in itself, over and above any harm this event involves for the nation's last members.

\section{Risk and Uncertainty}

Projects may differ in terms of how much visibility they afford. With some projects, moral value and cost are clearly predictable, but with other projects there are significant risks or even uncertainties. Let me briefly outline the latter distinction. A decision involves risk insofar as the decision 
maker does not know what will happen but can make reliable assumptions about the possible outcomes and their probabilities. A decision involves uncertainty insofar as the decision maker cannot make reliable assumptions about the probabilities associated with various outcomes or even about what the possible outcomes are. The distinction between decisions under risk and decisions under uncertainty is scalar-a matter of degree. For instance, one may know the value ("payoff") of one possible outcome and that its probability is between $40 \%$ and $45 \%$, and the value of another outcome and that its probability is between $35 \%$ and $50 \%$, but be ignorant of what would happen if neither of these outcomes came about. In this case, there is some uncertainty associated with the first two outcomes (their exact likelihood is unknown), and much uncertainty about other possible outcomes, because their exact probabilities and even their values are unknown.

To cope with risk, the standard method would estimate the moral value of a chancy project as its probability-weighted expected moral value. Insofar as the realized value of a project depends on chancy factors, different outcomes are possible. In this case, one estimates for each outcome its probability and the moral value the project would then realize. The probability-weighted expected moral value of the project is then calculated as the sum of these products (probability times conditional value). Likewise for risks regarding cost: Here one estimates the cost of a chancy project as its probability-weighted expected cost. Insofar as a project's cost depends on chancy factors, different outcomes are possible. In this case, one estimates for each outcome its probability and what the project would then cost. The probability-weighted expected cost of the project is then calculated as the sum of these products (probability times conditional cost). A chancy project's cost-effectiveness (ex ante) is then estimated as before-by dividing its (probability-weighted expected) moral value by its (probability-weighted expected) cost.

Is this a morally plausible way to assess chancy projects? Is it plausible, for instance, to assign equal moral value to (1) a $10 \%$ chance of saving 1,000 lives and (2) a 100\% chance of saving 100 lives? Egalitarians may respond that (1) should be preferred, because it spreads survival prospects more evenly. Although this is true in a sense, I find the ex ante sense in which it is true morally irrelevant. In the long run, both strategies save equal numbers of lives. And the fact that, under (1), many additional people were the objects of failed harm protection attempts - this fact is of no value to these people. What other moral value could it have?

Others think that (2) should be preferred. They may feel that, taking a gamble, (1) expresses disrespect for human life-a feeling I find hard to understand. Or, familiar with financial markets, they may feel that some risk premium should be levied on (1). In the financial world, such a risk premium is deemed appropriate because of the decreasing marginal utility of money. But there is no decreasing marginal value of human lives saved. 
Lacking compelling reasons for departing, in either direction, from an equal assignment of moral value, I conclude, then, regarding decision making under risk, that the cost-effectiveness of a chancy project should be understood to be its cost-effectiveness ex ante, calculated by dividing its probability-weighted expected moral value by its probability-weighted expected cost.

Coping with uncertainty is considerably harder. Some theorists have argued that uncertainty calls for a conservative response, one that gives great weight to the worst conceivable outcome. The most conservative strategy here is the so-called maximin rule. ${ }^{20}$ "Maximin" is short for the Latin "maximum minimorum," meaning highest minimum. The maximin rule instructs agents to choose the option that is associated with the best worst-case scenario. But this rule seems plainly too conservative here. To see this, consider a case like this: An INGO has a truck with perishable food in a region where starvation is widespread. The food is enough to protect up to 800 people from premature death (keeping them alive until harvest time, say). One option is to drive the food to a township in the east, where it would certainly protect 200 people from imminent starvation. The other option is to drive it west, where the food may save 800 people in a larger town. Although it is known that the township in the east is reachable by truck, information about whether the town in the west can be so reached is unavailable. Trying the route west will consume the available fuel and, should the truck not get through, the food will protect no one.

In this sort of case, I think one should reason as follows: If the town in the west is reachable, then going west would save 600 more starving people than going east. If the town in the west is not reachable, then going east would save 200 more people than going west would. Given the uncertainty, these two conditionals are symmetrically placed. There is only one factor that can break the symmetry: the larger number of people protected. Therefore, the truck should proceed toward the town in the west.

In the real world, the uncertainty about probabilities is typically less total than in this example. Some rough estimates are normally possible concerning the likelihoods of some of the outcomes. In the real world, however, there are often other sources of uncertainty, because agents may not even have a complete understanding of all possible outcomes. Each of the two projects in the example might be helped or hindered in myriad ways, and it is impossible to anticipate all these possibilities, let alone to attach rough probabilities to them. Still, the overall principle that should guide INGOs in coping with risk and uncertainty is clear enough. An INGO should incorporate risk and uncertainty into its decision making in such a way as to maximize its expected long-run cost-effectiveness. Put more generally:

$\left(A B C D^{*}\right)$ Other things being equal, an INGO should govern its decision making about candidate projects by such rules and procedures as are expected to maximize its long-run cost-effectiveness, defined as the expected aggregate moral 
value of the projects it undertakes divided by the expected aggregate cost of these projects. Here, aggregate moral value, or harm protection, is the sum of the moral values of the harm reductions (and increases) these projects bring about for the individual persons they affect.

\section{Fund-raising}

The projects an INGO undertakes have a feedback effect on its fund-raising success. And this INGO may then face complex choices between intrinsically more cost-effective projects on one hand and more donor-enticing projects on the other.

Consider the decision between two projects, each of which would cost $\$ 2$ million to implement. Project $\mathrm{G}$ has an estimated moral value of 9,000, whereas project $H$ has an estimated moral value of only 3,000. (Project $G$ might save 9,000 children from death by starvation, for instance, whereas project $\mathrm{H}$ would save 3,000 children from such a death.) One might then say that project G's intrinsic cost-effectiveness $(9,000 / 2$, score of 4,500$)$ is three times as great as the intrinsic cost-effectiveness of project $\mathrm{H}$ $(3,000 / 2$, score of 1,500$)$.

However, project $\mathrm{H}$ would be conducted in a current "hotspot" and therefore would draw a lot more media attention. This, in turn, would trigger extra contributions, which would reduce the "true" cost of project $\mathrm{H}$, or so one might think. Suppose the fund-raising experts predict that project $\mathrm{H}$ would raise incoming contributions by $\$ 1.5$ million, whereas project $\mathrm{G}$-conducted in some remote location-would raise incoming contributions by only $\$ 200,000$. If this is the situation, then one might say that the "true" cost-effectiveness of project $G$ is 9,000/1.8 (score of $5,000)$ and that the "true" cost-effectiveness of project $\mathrm{H}$ is $3,000 / 0.5$ (score of 6,000).

Which of the two methods of assessing the cost and cost-effectiveness of projects-intrinsic versus "true"-is correct? The answer, I believe, is neither. Focusing on intrinsic cost-effectiveness-perhaps on the grounds that the concern with fund-raising is profane or that the responsibility for how much money is received by an INGO rests solely with its potential contributors-unacceptably ignores the gain in harm protection that additional funds would make possible.

To appreciate why focusing on "true" cost-effectiveness is likewise unacceptable, one needs to draw a further distinction with regard to the additional contributions that projects may trigger. One needs to distinguish between additional contributions that constitute merely a redirection from one INGO to another and additional contributions that increase the sum total of funds received by all relevant INGOs. To mark this distinction, let us say that an INGO's projects may attract both substitutional and accretive contributions. In the former case, one INGO is substituted for another as recipient of part of the overall pool of relevant contributions. In the latter case, this whole pool is enlarged. 
This distinction may be unfamiliar because it has little significance in the business world, where talk of cost-effectiveness has its main home. When deciding whether to run an advertising campaign, a firm will assess the cost of the campaign against its expected benefits in terms of additional business and earnings. In considering these benefits, the firm need not care whether it is benefiting by taking business away from its competitors or by increasing overall demand. If anything, it will slightly prefer taking business away from competitors because this will have a greater impact on its market share and will also weaken its competitors in absolute terms. A firm has no reason to want its peers to be successful and effective in the pursuit of their goals.

The distinction has great significance, however, in the INGO world, where many INGOs pursue the same goals. Many INGOs, for instance, seek to protect children from hunger and malnutrition. Each such INGO has vastly more moral reason to be concerned that children be protected than it has reason to be concerned that such protection be provided by itself rather than by one of its peers.

To illustrate the point, consider two INGOs with such a common goal and assume that INGO tends to favor projects like $\mathrm{G}$, whereas $\mathrm{INGO}_{2}$ tends to favor projects like $\mathrm{H}$. Insofar as the pool of contributions is fixed, the result will be that the cost-effectiveness of the two INGOs, considered as a team, will gradually decline. This is so because the diverse project policies of the two organizations will divert contributions from $\mathrm{INGO}_{1}$ to $\mathrm{INGO}_{2}$. This has the effect that more and more of the projects they initiate will be type-H projects initiated by $\mathrm{INGO}_{2}$, rather than type- $\mathrm{G}$ projects initiated by $\mathrm{INGO}_{1}$. By diverting funding from INGO to itself, $\mathrm{INGO}_{2}$ is reducing the cost-effectiveness of these contributions by two thirds (because type- $G$ projects are three times as cost-effective as type- $\mathrm{H}$ projects).

Seeing how its funding is drying up, $\mathrm{INGO}_{1}$ can follow $\mathrm{INGO}_{2}$ 's example by likewise switching its activities toward projects of type $\mathrm{H}$. Doing so may help INGO stem the decline in its funding. However, it will also accelerate the overall drift from type-G to type-H projects. Whether INGO ${ }_{1}$ makes the switch, over time, ever more of the money raised by the two INGOs will go to projects of type $\mathrm{H}$ rather than to projects of type G. Furthermore, on the assumption of a fixed pool of contributions, this is a disaster, rendering these contributions much less cost-effective in terms of harm protection than they would be if devoted to projects of type $\mathrm{G}^{21}$

Insofar as high-profile projects will bring in contributions that would not otherwise have been made, the shift to type-H projects may be desirable, as is illustrated by the "true" cost-effectiveness calculation conducted earlier. A key to deciding between projects $\mathrm{G}$ and $\mathrm{H}$, then, is an empirical estimate about the extent to which new funds raised through projects $G$ and $\mathrm{H}$ are substitutional or accretive.

The correct way of calculating the cost and cost-effectiveness of projects takes account of new funds, which the candidate projects would attract, 
only insofar as these are accretive. In the numerical example provided earlier, INGOs should choose type-H projects over type-G projects only if the new funds the former would raise are almost entirely accretive. This is based on the assumption that an INGO should aim for harm protection in general, regardless of how much thereof it itself achieves.

This discussion of fund-raising illustrates a somewhat more general point. An INGO can pursue an agent-relative goal, defined in terms of the moral value it realizes, or the corresponding agent-neutral goal, defined in terms of the moral value all INGOs together realize. As the example has shown, pursuit of the former goal may well detract from achievement of the latter by worsening the allocation of funds within and among INGOs.

In addition, pursuit of the agent-relative goal is also directly collectively self-defeating. ${ }^{22}$ Each INGO does worse, even in terms of this goal, if all INGOs successfully pursue it than it would do if all INGOs successfully pursued the agent-neutral goal instead. An INGO seeking to maximize the moral value it itself realizes will favor type-H projects over type-G projects. Others must follow suit or be driven out of the business of harm protection. When all INGOs focus their resources on type-H projects, however, each will realize less moral value than it would realize if all INGOs focused their resources on type-G projects.

Because the agent-neutral goal is morally more plausible and because the agent-relative goal is directly collectively self-defeating, INGOs ought to be committed to the agent-neutral goal and should therefore understand cost in ( $\left.\mathrm{ABCD}{ }^{*}\right)$ in the sense of correct cost.

But what should any one INGO do if other INGOs are "defecting" to the agent-relative goal? Should it stick to the agent-neutral goal, accepting the consequent reduction in its funding? Should it likewise defect, accepting the consequent reduction in global INGO effectiveness? Or should it try to raise the issue with other INGOs and the contributing public?

\section{Deontological Concerns: Discriminating Contributors}

My discussion thus far of moral priorities for INGOs has resulted in a broadly consequentialist conception. To be sure, this conception is not consequentialist in the traditional sense. It does not instruct us simply to maximize the good, defined as harm reduction, but instead gives greater weight to protecting from harm those who are worse off (proposition [B]). Some theorists hold that this prioritarian element suffices to render a moral conception recognizably deontological. ${ }^{23}$ In my view, however, a conception that instructs us to maximize some weighted aggregate (weighted in favor of those worse off, in this case) is still broadly consequentialist; it merely conceives morally relevant consequences a little differently. This is a terminological squabble among philosophers that need not detain us. I mention it only to flag that I now discuss more significantly deontological concerns. 
Thus far I have argued that INGOs ought to focus their resources on the projects that are most cost-effective. This claim implies that INGOs ought to discriminate in favor of badly off people who can be cheaply protected from harm and thus against badly off people whom it would be expensive to protect. I have accepted this implication as plausible; such discrimination is not morally offensive in any way insofar as it is driven entirely by the concern to protect as many badly off people as possible (proposition [C]).

But now consider this complication. Suppose the affluent people giving money to INGOs are mostly white and somewhat racist. Projects that protect from harm badly off white people elicit much greater gains in accretive contributions per dollar expended than alternative projects that protect from harm equally badly off persons of color. (Judging by the public responses to the crises in Rwanda and Kosovo, this supposition is anything but unrealistic.) To illustrate the difficulty, consider the choice between two projects. Project $\mathrm{K}$ is targeted at badly off whites and project $\mathrm{L}$ is targeted at badly off blacks. Ignoring feedback effects on fund-raising, project $\mathrm{L}$ is considerably more cost-effective (in the intrinsic sense). Because project $\mathrm{K}$ would produce much greater gains in accretive contributions, however, project $\mathrm{K}$ is considerably more cost-effective on (what I have argued is) the correct understanding of cost-effectiveness. Given all that has been said thus far, then, the INGO ought to implement type-K projects over type-L projects. Is this plausible?

One may be tempted to try to avoid this hard question by pointing out, correctly, that the attitudes of affluent people are subject to change. An INGO might engage in a publicity campaign designed to foster sentiments of identification and solidarity also with badly off people of color. This is true enough, but it does not answer the difficulty. Any such publicity campaign diverts funds that could have been expended on harm protection projects. To be sure, this diversion can be justified-when it would increase the harm protection all INGOs achieve in the long run, for instance, by increasing the willingness to support type-L projects, by winning accretive contributions through improved INGO reputation, and by reducing the sense of exclusion and humiliation among poor blacks abroad. Still, such diversion would often be unjustified. Therefore, if correct cost-effectiveness is what matters, then an INGO faced with a situation like the one described often ought to leave the racist attitudes of its contributors alone and focus its resources on projects of type K. Does this show that the focus on correct cost-effectiveness needs to be modified?

There are essentially five responses to this difficulty. The first argues that there is nothing morally wrong with contributor racism or, more generally, with contributors directing their harm reduction efforts toward projects of their choice. It is their money, after all, and, just as they may freely decide what movies to watch or whom to go out with, so they are equally free, morally, to decide which good causes to support. I disagree with this first response on two counts. As the next subsection brings out, 
I believe that, in the world as it is, our moral reasons to support efforts at harm protection are not exclusively positive (in the sense of positive duties). Rather, our contributions are morally required by more stringent duties arising from our material involvement in the production of harm. Moreover, even if we had only positive moral reasons to contribute to INGOs, it would still be morally odious to favor some badly off people merely because of their skin color. The stronger such favoritism, the more offensive it is morally.

The second response argues that contributor racism is indeed regrettable, but that there is nothing morally questionable about an INGO taking account of such contributor racism as an empirical fact in its effort to optimize its harm protection strategy. Again, I cannot share this response. To be sure, the INGO is intending to do the best it can toward realizing moral value and has no sympathy for the racism of its contributors. Still, it implements this racism, and this is morally offensive even when done in the service of a good cause.

The third response argues that it is indeed morally offensive for an INGO to implement contributor racism, but that this significant reason for favoring type-L projects is usually overwhelmed in our world by the great moral importance of achieving harm protection. The reason against allowing oneself to implement racism can then be permitted to tip the scale only when competing projects are, as far as can be estimated, close in cost-effectiveness correctly assessed. If one project is much superior in this respect, like project $\mathrm{L}$ is superior to project $\mathrm{K}$, then the superior project ought to be chosen, albeit with a sense that one is thereby participating in a wrong done to those whom project $\mathrm{K}$ would have protected. I find this the most plausible response.

The fourth response argues that the concerns of combating racist attitudes among contributors and of not allowing oneself to become an instrument of racism have enough weight to affect the balance of moral reasons even with many early deaths at stake on the other side. This moral reason must then be traded off against the others. Thus, it may well be that we ought stand up for the principle that all children matter equally and save 10 black children from death by starvation, even if focusing on white children would have generated accretive contributions that would have enabled us to save more. This response also strikes me as having some appeal, although I do not know how one can answer the question how many extra deaths this "standing up for principle" can justify. What is the correct exchange rate between racism spurned and additional lives saved? As this exchange rate is increased so that standing up for principle becomes really costly in terms of harm protection, this response quickly becomes implausible to me.

The fifth response, in absolutist deontological fashion, gives overriding priority to the antiracist principle. When it comes to factors such as sex and skin color, we must simply ignore accretive contributions and focus solely on the intrinsic cost-effectiveness of projects. If following 
this criterion diminishes, even greatly, the harm protection we can achieve, then we must simply accept this diminution. In view of the huge difference our choice of harm protection strategy makes in terms of severe human suffering, I find this response unacceptable. The next subsection implicitly undermines one main source of its appeal - the deontological idea that one should not wrong some people to help others. Whatever the merits of this idea (it is implausible when understood as an absolute constraint), its relevance in this world is severely limited because most of what we, through INGOs, do to protect people in the poor countries is morally required from us not merely under the label of help or positive duty, but also as mitigation of wrongs from which we profit and in the production of which we participate.

\section{Deontological Concerns: Material Involvement}

The discussion so far suggests a broadly consequentialist approach, roughly: The greater the harm protection we can achieve, the more reason we have to achieve it. This suggestion is fine as long as other things are presumed to be equal. One pivotal factor that may not be equal, however, is how we, the INGO and its contributors, are causally related to the harm in question. We normally think of INGOs as fulfilling a merely positive moral responsibility to prevent or to mitigate harm suffered by others. International nongovernmental organizations may, however, also fulfill a negative moral responsibility not to cause harm.

It is often foreseeable that candidate INGO projects would harm innocent people. It may be foreseeable, for example, that warring factions will rob some of the resources we might dispatch into some volatile region and will then use them to inflict further violence. By fueling the fighting, these projects would thus cause harm. In such cases, the unmodified $\left(\mathrm{ABCD}^{*}\right)$ may still be a plausible guiding principle, provided the available evidence does not allow us to identify any persons for whom the project's expected moral value is negative. But often we do have such evidence. We know which armed group is able and disposed to loot our resources, and we know who its intended victims are. In such cases, the ordinary cost-effectiveness reasons against choosing this project (see "Distributive Fairness") are enhanced by a negative moral responsibility not to add to the (risk of) harm suffered by such potential victims.

Another category of moral reasons is to prevent or to mitigate harm that one otherwise will have caused or have participated in causing. Such intermediate moral reasons can be relevant to INGO work in special cases in which INGO staff have-wrongfully, negligently, or even innocentlyset in motion a train of events that threatens to harm innocent people. In such cases, the INGO's moral reason to protect them from these harms is more stringent than it would be if this INGO had not been materially involved in causing this threat. 
The persistence of severe poverty in many poor countries is partly the result of the design of the global institutional order that foreseeably (re)produces vastly more poverty than would be reasonably avoidable. Had the rich countries pursued a different path of globalization during the past 20 years, the problem of severe poverty would be a fraction of its current size. Insofar as we citizens of rich countries (through our governments) participate in, or profit from, the imposition of this unjust order, we are materially involved in most of the harm human beings are suffering worldwide. International nongovernmental organizations and their contributors therefore rarely face actual hard choices between morally less valuable harm reductions that we have intermediate moral reasons to achieve and morally more valuable harm reductions that we have only positive moral reason to achieve.

Only a small fraction of the citizens of the rich countries are willing to contribute to averting such harm. Their contributions are nowhere near sufficient to avert all the harm that the citizens of the rich countries have intermediate moral duties to avert. In the context of this grievous injustice, we should, for the most part, direct our grossly insufficient contributions for maximum effect: toward the most cost-effective harm protection projects. Reflection on intermediate moral duties thus greatly increases the strength of our moral reasons to achieve cost-effective harm protection without justifying significant departures from $\left(A B C D^{*}\right)$.

Discussions of this essay suggest that most readers will sharply disagree with some of my conclusions. Fortunately, they also suggest that we all have a great deal to learn from a careful elaboration of, and engagement with, this view.

\section{Notes}

This chapter is an abbreviated and updated version of my "Moral Priorities for International Human Rights NGOs," in Daniel A. Bell and Jean-Marc Coicaud, eds., Ethics in Action: The Ethical Challenges of International Human Rights Nongovernmental Organizations (Tokyo: United Nations University Press, 2007), pp. 218-256. Many thanks to Matt Peterson and Leif Wenar for their help in adapting and revising it.

1. Food and Agriculture Organization, "1.02 Billion People Hungry," June 19, 2009, www.fao.org/news/story/en/item/20568/icode/ (accessed June 26, 2009).

2. World Health Organization, UNICEF, Progress on Drinking Water and Sanitation: Special Focus on Sanitation (New York and Geneva: UNICEF and World Health Organization, 2008), www.who.int/water_sanitation_health/ monitoring/jmp2008/en/index.html, p. 30.

3. Ibid., p. 13.

4. Fogarty International Center for Advanced Study in the Health Sciences, Strategic Plan: Fiscal Years 2000-2003 (Bethesda, Md.: National Institutes of Health, n.d.), www.fic.nih.gov/about/plan/exec_summary.htm.

5. United Nations-Habitat, The Challenge of Slums: Global Report on Human Settlements 2003 (London: Earthscan, 2003), p. vi. 
6. United Nations-Habitat, "Urban Energy," www.unhabitat.org/content.asp?c $\mathrm{id}=2884$ \& catid=356\&typeid=24\&subMenuId $=0$ (July 24, 2010).

7. UNESCO Institute for Statistics, "Literacy Topic," December 1, 2008, www.uis.unesco.org/ev.php?URL_ID =6401\&URL_DO=DO_TOPIC\& URL_SECTION=201.

8. See International Labour Office, The End of Child Labour: Within Reach (Geneva: International Labour Office, 2006), p. 6.

9. This is the World Bank's official poverty line, most recently redefined in terms of daily consumption, the local cost of which has the same purchasing power as \$1.25 had in the United States in 2005. See Shaohua Chen and Martin Ravallion, "The Developing World Is Poorer Than We Thought, But No Less Successful in the Fight against Poverty," World Bank Policy Research Working Paper WPS 4703 (Washington, D.C., World Bank Development Research Group, 2008), pp. 10, 44; econ.worldbank.org/docsearch.

10. World Health Organization, Global Burden of Disease: 2004 Update (Geneva: WHO, 2008), table Al, pp. 54-59, www.who.int/healthinfo/global_ burden_disease/2004_report_update/en/index.html.

11. UNICEF, The State of the World's Children 2008 (New York: UNICEF, 2008), p. iii; United Nations Development Programme, Human Development Report 2003 (New York: Oxford University Press, 2003), pp. 310-330; United Nations Research Institute for Social Development, Gender Equality: Striving for Justice in an Unequal World (Geneva: UNRISD/UN Publications, 2005); Social Watch, Unkept Promises (Montevideo: Instituto del Tercer Mundo, 2005), www. socialwatch.org/node/10021.

12. Thomas Pogge, World Poverty and Human Rights: Cosmopolitan Responsibilities and Reforms, 2nd ed. (Cambridge: Polity Press, 2008), chap. 8.

13. Or $73 \%$ of world income. See World Bank, World Development Report 2010 (Washington, D.C.: World Bank, 2010), p. 379, go.worldbank.org/BKLQ 9DSDU0.

14. See millenniumindicators.un.org/unsd/mdg/SeriesDetail.aspx? srid $=592 \&$ crid=. The latest figures currently available are for 2008 .

15. United Nations Development Programme, Human Development Report 2003, p. 290, hdr.undp.org/en/reports/global/hdr2003.

16. Compare Derek Parfit, "Equality or Priority," in Matthew Clayton and Andrew Williams, eds., The Ideal of Equality (Houndmills: Macmillan, 2000), pp. 81-125, and John Broome, "Equality Versus Priority: A Useful Distinction," 2002, users.ox.ac.uk/ sfop0060/.

17. Paul Collier and David Dollar, "Aid Allocation and Poverty Reduction," European Economic Review 46 (2002), pp. 1475-1500, 1488.

18. Ibid., p. 1497.

19. Ibid., pp. 1488 and 1490.

20. For example, John Rawls, A Theory of Justice (Cambridge, Mass.: Harvard University Press, 1999 [1971]), pp. 132-135.

21. For the claim that something like this is actually happening, pursuant to what he calls the "humanitarian Gresham's Law," see Alex de Waal, Famine Crimes: Politics and the Disaster Relief Industry in Africa (Bloomington: Indiana University Press, 1998), pp. 138-143.

22. See Derek Parfit, Reasons and Persons (Oxford: Oxford University Press, 1984), chap. 4.

23. An example is John Rawls, A Theory of Justice, pp. 22-23 and 26. 